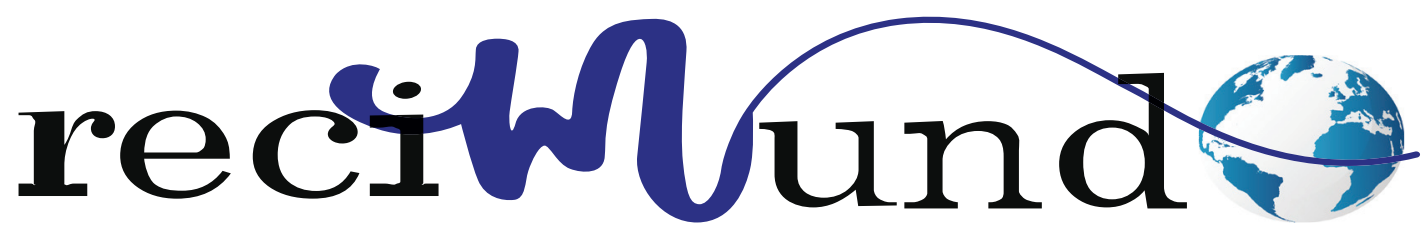

Revista Científica Mundo de la Investigación y el Conocimiento

DOI: 10.26820/recimundo/5.(4).oct.2021.45-52

URL: https://recimundo.com/index.php/es/article/view/1296

EDITORIAL: Saberes del Conocimiento

REVISTA: RECIMUNDO

ISSN: 2588-073X

TIPO DE INVESTIGACIÓN: Artículo de revisión

CÓDIGO UNESCO: 32 Ciencias Médicas

PAGINAS: 45-52

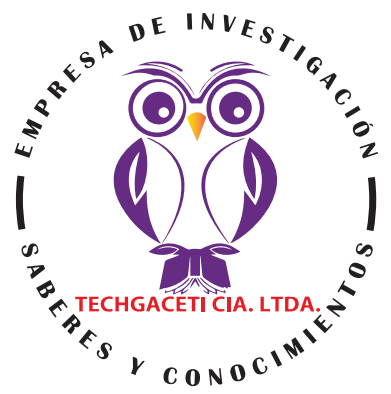

\title{
Meningitis bacteriana en paciente pediátrico
}

Bacterial meningitis in a pediatric patient Meningite bacteriana em paciente pediátrico

Katherine Solange Beltrán Parreño; Anahi Amparo Guerra García²; Pablo David Parra Parra3;

Katty Elizabeth Huanca Jumbo ${ }^{4}$

RECIBIDO: 02/09/2021 ACEPTADO: 20/09/2021 PUBLICADO: 30/10/2021

1. Médico General; Investigador Independiente; Quito, Ecuador; solangekbeltranp@gmail.com; (DD https://orcid.org/00000002-2254-4506

2. Médico General; Investigador Independiente; Quito, Ecuador; ani_g45@hotmail.com; (DD https://orcid.org/0000-0003-45683266

3. Médico General; Investigador Independiente; Quito, Ecuador; daviid9464@gmail.com; (iD https://orcid.org/0000-00024878-1729

4. Médico General; Investigador Independiente; Quito, Ecuador; kattyelizahuanca@hotmail.es; (DD https://orcid.org/00000002-0288-3973

\section{CORRESPONDENCIA}

Katherine Solange Beltrán Parreño

solangekbeltranp@gmail.com

Quito, Ecuador 


\section{RESUMEN}

La meningitis es un síndrome neurológico de etiología bacteriana o aséptica, si es identificada a tiempo con un tratamiento apropiado, del 8 al 15\% de los afectados fallecen usualmente dentro de las primeras 24 a 48 horas luego de la aparición de la sintomatología. Por otro lado, del 10 al 20\% de los que sobreviven a esta condición son susceptibles a padecer consecuencias permanentes, que se reflejan en pérdida auditiva, problemas de aprendizaje y daño cerebral. La metodología de la investigación, es una revisión bibliográfica apoyada en medios electrónicos como páginas web (SCOPUS, PubMed, Biblioteca Cochrane, Google Scholar), en donde se encontró una amplia variedad de artículos de investigación que abordan la temática estudiada, el objetivo es recopilar la información más relevante de dichos autores para realizar una síntesis bien completa, que pueda ayudar a futuras investigaciones. La meningitis bacteriana es una afección que debe diagnosticarse dentro de las primeras 48 horas, ya que su evolución y pronostico son inciertas. Es por ello, que el diagnóstico oportuno, así como el estudio de los factores externos que la provoco, es fundamental para evitar un agravamiento de la condición del paciente. Después de que se confirma el diagnóstico de la meningitis, se debe iniciar el tratamiento con antibióticos empíricos, esperando la identificación del tipo o subtipo de meningitis por los departamentos de microbiología. Si luego de iniciado el tratamiento se logra estabilizar al paciente y supera la enfermedad, es probable que se puedan generar secuelas neurológicas, es por ello que es vital el seguimiento y control de la evolución del paciente para seguir con su recuperación.

Palabras clave: Meningitis, Bacteriana, Sintomatología, Neurológicas, Tratamiento.

\section{ABSTRACT}

Meningitis is a neurological syndrome of bacterial or aseptic etiology, if it is identified in time with appropriate treatment, 8 to $15 \%$ of those affected usually die within the first 24 to 48 hours after the onset of symptoms. On the other hand, 10 to $20 \%$ of those who survive this condition are susceptible to permanent consequences, which are reflected in hearing loss, learning disabilities and brain damage. The research methodology is a bibliographic review supported by electronic media such as web pages (SCOPUS, PubMed, Cochrane Library, Google Scholar), where a wide variety of research articles were found that address the subject studied, the objective is to collect the most relevant information from these authors to make a complete synthesis, which may help future research. Bacterial meningitis is a condition that must be diagnosed within the first 48 hours, since its evolution and prognosis are uncertain. That is why the timely diagnosis, as well as the study of the external factors that cause it, is essential to avoid a worsening of the patient's condition. After the diagnosis of meningitis is confirmed, treatment with empirical antibiotics should be started, awaiting identification of the type or subtype of meningitis by the microbiology departments. If, after starting the treatment, the patient is stabilized and the disease is overcome, it is likely that neurological sequelae may be generated, which is why it is vital to monitor and control the patient's evolution to continue with his recovery.

Keywords: Meningitis, Bacterial, Symptomatology, Neurological, Treatment.

\section{RESUMO}

A meningite é uma síndrome neurológica de etiologia bacteriana ou asséptica, se identificada a tempo com tratamento adequado, 8 a 15\% dos acometidos costumam morrer nas primeiras 24 a 48 horas após o início dos sintomas. Por outro lado, 10 a 20\% dos que sobrevivem a essa condição são suscetíveis a consequências permanentes, que se refletem em perda auditiva, dificuldades de aprendizagem e danos cerebrais. A metodologia da pesquisa é uma revisão bibliográfica apoiada em meios eletrônicos como páginas web (SCOPUS, PubMed, Cochrane Library, Google Scholar), onde foram encontrados diversos artigos de pesquisa que abordam o assunto estudado, o objetivo é coletar os mais relevantes informações desses autores para uma síntese completa, o que pode auxiliar pesquisas futuras. A meningite bacteriana é uma condição que deve ser diagnosticada nas primeiras 48 horas, pois sua evolução e prognóstico são incertos. Por isso, o diagnóstico atempado, assim como o estudo dos fatores externos que o provocam, é fundamental para evitar o agravamento do estado do doente. Confirmado o diagnóstico de meningite, deve-se iniciar o tratamento com antibióticos empíricos, aguardando a identificação do tipo ou subtipo de meningite pelos serviços de microbiologia. Se, após o início do tratamento, o paciente estiver estabilizado e a doença superada, é provável que surjam sequelas neurológicas, por isso é imprescindível monitorar e controlar a evolução do paciente para continuar sua recuperação.

Palavras-chave: Meningite Bacteriana, Sintomatologia Neurológica, Tratamento. 


\section{Introducción}

La meningitis es un síndrome neurológico de etiología bacteriana o aséptica. La meningitis bacteriana (MB) es causante de alta morbilidad y mortalidad, la última alcanza 12 a 50\% en países subdesarrollados a pesar del tratamiento. Por el contrario, la meningitis aséptica (MA), frecuentemente de etiología viral, es autolimitada y se asocia con mejor pronóstico (Uribe-Ocampo, Correa-Pérez, Rodríguez-Padilla, Barrientos-Gómez, \& Orozco-Forero, 2018, pág. 122). Si es identificada a tiempo con un tratamiento apropiado, del 8 al $15 \%$ de los afectados fallecen usualmente dentro de las primeras 24 a 48 horas luego de la aparición de la sintomatología. Por otro lado, del 10 al $20 \%$ de los que sobreviven a esta condición son susceptibles a padecer consecuencias permanentes, que se reflejan en pérdida auditiva, problemas de aprendizaje y daño cerebral (Merchán Beltrán, 2020, pág. 6).

Para el diagnóstico médico de Meningitis es importante conocer la etiología de la misma, por ello se debe establecer si es de origen viral o bacteriana, a través de los diferentes criterios en función del estadio clínico, pruebas de laboratorio como: cultivos que representan alta sensibilidad para aislar el germen patógeno causante y a su vez la confirmación de un caso sospechoso. Los agentes etiológicos más comunes son: "Streptococcus pneumoniae, Neisseria meningitidis y Haemophilus influenzae", por supuesto también se debe valorar las condiciones clínico-geográficas en las que se desenvuelve el individuo y considerar factores internos como: la edad, sexo y manifestaciones clínicas del paciente (Neira Serrano, 2019, pág. 4).

La mortalidad alcanza $37 \%$, aumenta en relación directa con el incremento de los factores de riesgo producidos por un mal pronóstico, y en los adultos supervivientes las secuelas neurológicas se estiman en $52 \%$. Estos factores de mal pronóstico favorecen un aumento de las complicaciones como lo son: las sistémicas (falla cardiaca, coagulación intravascular diseminada, hiponatremia) y las neurológicas (edema cerebral, crisis convulsivas, hidrocefalia, vasculitis del sistema nervioso central, déficits visuales, afasia, hipoacusia, déficits motores, lesión de nervios craneales). Las complicaciones menos comunes serían los abscesos cerebrales, la ventriculitis, las colecciones subdurales infectadas (empiema) o estériles (higromas) (Moreira, y otros, 2019, pág. 420).

Cabe mencionar que a nivel mundial que se incorporó la vacuna para prevención de meningitis y neumonía provocada por Haemophilus influenzae tipo b; existentes en tres dosis que forman parte del esquema de vacunación en 191 países. En el continente americano es donde más han sido implementadas siendo el $90 \%$ de la población quienes han tenido acceso a recibir la inmunización, tristemente en el Pacífico Occidental alcanza no más del 28\%. Para satisfacción de la población asiática en el año 2016 consiguieron llegar al 80\% de cobertura (Fajardo Barreto \& Guevara García, 2018, pág. 6).

\section{Sintomatología y cuadro clínico}

En la mayoría de los niños y adultos, la meningitis bacteriana aguda comienza con síntomas que empeoran lentamente durante 3 a 5 días. Estos síntomas pueden incluir una sensación de malestar general, fiebre, irritabilidad y vómitos. Algunos pacientes presentan dolor de garganta, tos y secreción nasal. Estos síntomas vagos pueden parecerse a los de una infección vírica. 2 Los síntomas iniciales que sugieren meningitis son:

- Fiebre

- Cefalea

- Rigidez de nuca (por lo general)

- Confusión o disminución del estado de alerta 
- Sensibilidad a la luz (Solórzano, Pincay, Andrade, \& Domínguez, 2018, pág. 157).

\section{Diagnóstico}

En la analítica general los hallazgos son inespecíficos. En el hemograma se suele encontrar leucocitos con predominio de formas inmaduras, aunque en casos de infección severa puede aparecer leucopenia y trombopenia. Se debe realizar estudio de coagulación para descartar una coagulación intravascular diseminada (CID). Otras alteraciones analíticas nos van a dar una idea de la severidad del cuadro (acidosis metabólica, hiperlactacidemia, hiponatremia.

Tabla 1. Estudios de laboratorios para determinación de meningitis

\begin{tabular}{|c|c|}
\hline Determinaciones en suero & $\begin{array}{l}\text { - Recuento de leucocitos: tiene la menor capacidad predictiva de MB por debajo de } \\
\text { la PCR y la PCT. } \\
\text { - PCR: Se ha de ser cauto en su interpretación porque su elevación se produce } \\
\text { también en procesos inflamatorios y víricos. } \\
\text { - Procalcitonina (PCT): Parece razonable considerar siempre la posibilidad de una } \\
\text { MB cuando la PCT inicial sea }>0,25-0,5 \mathrm{ng} / \mathrm{ml} \text {. La PCT supera a la PCR en los } \\
\text { pacientes pediátricos, en adultos y en los ancianos, sin las limitaciones que presenta } \\
\text { la PCR. } \\
\text { - Lactato sérico: no tiene capacidad para distinguir la etiología bacteriana de la } \\
\text { vírica ni otras causas de síndrome de respuesta inflamatoria sistémica (SRIS) no } \\
\text { infeccioso. Por tanto, su uso en las meningitis agudas se recomienda como factor } \\
\text { pronóstico de gravedad y mortalidad, y como respuesta al tratamiento. }\end{array}$ \\
\hline Hemocultivos & $\begin{array}{l}\text { Los hemocultivos (HC) son positivos en un } 50-90 \% \text { de los casos, particularmente en } \\
\text { casos de meningitis meningocócica, bajando la rentabilidad si se toman tras la } \\
\text { administración de antibioterapia }\end{array}$ \\
\hline $\begin{array}{l}\text { Estudio de líquido } \\
\text { cefalorraquídeo }\end{array}$ & $\begin{array}{l}\text { Esencial para el diagnóstico de meningitis, permitiendo establecer el diagnóstico de } \\
\text { infección del SNC y diferenciar las infecciones bacterianas de las no bacterianas. La } \\
\text { realización de la punción lumbar (PL) debe ser precoz, y no debe demorarse por la } \\
\text { realización de pruebas de imagen. Al realizar la PL es conveniente medir presión en el } \\
\text { LCR (utilizar reglas desechables de presión raquídea disponibles en el hospital). }\end{array}$ \\
\hline Determinaciones en LCR & $\begin{array}{l}\text { - Recuento de leucocitos: El número total de leucocitos en el LCR presenta un } \\
\text { menor rendimiento diagnóstico que el resto de parámetros estudiados en el LCR. } \\
\text { - Proporción de PMN: Junto con la disminución de la glucorraquia y la } \\
\text { concentración del lactato en LCR, son las determinaciones con significación } \\
\text { estadística, a partir del } 50 \% \text { de PMN, predictoras de MB frente a MV. } \\
\text { - Proteinorraquia: La gran mayoría de estudios recientes en niños, adultos y } \\
\text { ancianos publican una menor capacidad predictiva en comparación con la } \\
\text { proporción de PMN, glucorraquia o concentración de lactato. } \\
\text { - Glucorraquia: El valor de glucosa en LCR no es el parámetro más adecuado para } \\
\text { diferenciar entre las meningitis agudas, sino el cociente entre la glucorraquia y la } \\
\text { glucemia, y se establece que el punto de corte del cociente (glucosa LCR)/(glucosa } \\
\text { sérica) de } 0,36 \text { obtiene un excelente resultado, con una sensibilidad del 92,9\% y una } \\
\text { especificidad también del } 92,9 \% \text {. } \\
\text { - Lactato: Su concentración en LCR es independiente de la del lactato sérico, por lo } \\
\text { que no hay que interpretar su concentración sérica como se debe hacer con la } \\
\text { glucorraquia, aunque debe tenerse en cuenta que sus valores disminuyen } \\
\text { notablemente si se ha administrado una pauta previa de antibioterapia. Es el } \\
\text { marcador diagnóstico más seguro de MB entre las determinaciones que se analizan } \\
\text { en el LCR. } \\
\text { - PCR: Es útil en casos con LCR negativos para tinción y cultivo y pacientes } \\
\text { pretratados. Presenta una mayor rapidez (160 min) y mayor sensibilidad que los } \\
\text { métodos convencionales. } \\
\text { - PCT: Una publicación reciente compara la potencia diagnóstica de la PCT en suero } \\
\text { y en LCR, concluyendo que la determinación en suero es mucho más útil que en } \\
\text { LCR y en la actualidad no se recomienda su evaluación en el LCR. } \\
\text { - Tinción de Gram. } \\
\text { Deteción de antígenos bacterianos con técnicas inmunológicas: Las técnicas } \\
\text { disponibles son la aglutinación con látex (AL), contrainmunoelectroforesis y } \\
\text { enzimoinmunoanálisis. Se basan en la detección rápida de polisacáridos capsulares } \\
\text { específicos, siendo particularmente útiles en pacientes pretratados con tinción de } \\
\text { Gram y cultivos negativos. }\end{array}$ \\
\hline
\end{tabular}

Fuente: Elaboración propia. Tomado de (Caballero, García, González, Fuentes, \& Díaz, 2017). 


\section{Tratamiento}

Las estrategias utilizadas para mejorar los resultados clínicos de la meningitis bacteriana incluyen el diagnóstico precoz y el inicio de la antibioticoterapia para optimizar la muerte bacteriana y disminuir la respuesta inflamatoria en el espacio subaracnoideo.

\begin{tabular}{|c|c|c|c|}
\hline Edad & $\begin{array}{l}\text { Antibiótico } \\
\text { elección }\end{array}$ & de & Dosis \\
\hline $\begin{array}{l}3 \text { meses a } 18 \\
\text { años }\end{array}$ & $\begin{array}{l}\text { Cefotaxima } \\
\text { ceftriaxona } \\
\text { vancomicina } \\
\text { rifampicina }\end{array}$ & $\begin{array}{r}0 \\
\text { más } \\
0\end{array}$ & $\begin{array}{l}\text { Ceftriaxona } 50 \mathrm{mg} / \mathrm{kg} \text { cada } 12 \mathrm{~h} \text { (máximo } 2 \mathrm{~g} \text { cada } 12 \mathrm{~h} \text { ). } \\
\text { Cefotaxima } 75 \mathrm{mg} / \mathrm{kg} \text { cada } 6-8 \mathrm{~h} \\
\text { Vancomicina } 10-15 \mathrm{mg} / \mathrm{kg} \text { cada } 6 \text { h para lograr } \\
\text { concentraciones séricas mínimas de } 15 \text { a } 20 \mathrm{mcg} / \mathrm{ml} \\
\text { Rifampicina } 10 \mathrm{mg} / \mathrm{kg} \text { cada } 12 \mathrm{~h} \text { hasta } 600 \mathrm{mg} / \mathrm{día}\end{array}$ \\
\hline
\end{tabular}

Figura 1. Tratamiento antibiótico empírico para meningitis bacteriana adquirida en la comunidad

Fuente: (Tolosa-Quintero, 2020)

\begin{tabular}{|c|c|c|}
\hline Microrganismo & Tratamiento recomendado & Duración \\
\hline $\begin{array}{l}\text { Streptococcus pneumoniae } \\
\text { - Susceptible a penicilina (MIC }<0.1 \mu \mathrm{g} / \mathrm{MI} \text { ) } \\
\text { - Resistente a penicilina (MIC >0.1 } \mathrm{\mu g} / \mathrm{MI} \text { ) o } \\
\text { Susceptible a cefalosporinas de } 3 \mathrm{ra} \\
\text { generación (MIC }<2 \mu \mathrm{g} / \mathrm{MI}) \\
\text { - Resistente a cefalosporinas de } 3 \mathrm{ra} \\
\text { generación (MIC }>2 \mu \mathrm{g} / \mathrm{MI})\end{array}$ & $\begin{array}{l}\text { - Penicilina o amoxicilina/ampicilina } \\
\text { - Ceftriaxona o cefotaxima } \\
\text { - Vancomicina más rifampicina o vancomicina } \\
\text { más ceftriaxona/ cefotaxima/ o rifampicina } \\
\text { más cefotaxima/ceftriaxona }\end{array}$ & 10-14 dias \\
\hline $\begin{array}{l}\text { Neisseria meningitidis } \\
\text { - Susceptible a penicilina (MIC }<0.1 \mu \mathrm{g} / \mathrm{MI} \text { ) } \\
\text { - Resistente a penicilina (MIC }>0.1 \mu \mathrm{g} / \mathrm{MI})\end{array}$ & $\begin{array}{l}\text { - Penicilina o amoxicilina/ampicilina } \\
\text { - Ceftriaxona o cefotaxima }\end{array}$ & 7 dias \\
\hline Listeria monocytogenes & - Penicilina o amoxicilina/ampicilina & $\begin{array}{l}\text { Al menos } 21 \\
\text { dias }\end{array}$ \\
\hline $\begin{array}{l}\text { Haemophilus influenzae } \\
\text { - } \quad \beta \text {-Lactamasa negativo } \\
\text { - } \beta \text {-Lactamasa positivo }\end{array}$ & $\begin{array}{l}\text { - Amoxicilina o ampicilina } \\
\text { - Ceftriaxona o cefotaxima }\end{array}$ & $7-10$ dias \\
\hline $\begin{array}{l}\text { Staphylococcus aureus } \\
\text { - Meticilino sensible } \\
\text { - Meticilino resistente } \\
\text { - Resistente a vancomicina (MIC }>2 \mu \mathrm{g} / \mathrm{MI} \text { ) }\end{array}$ & $\begin{array}{l}\text { - Oxacilina } \\
\text { - Vancomicina } \\
\text { - Linezolid }\end{array}$ & $\begin{array}{l}\text { Al menos } 14 \\
\text { dias }\end{array}$ \\
\hline
\end{tabular}

Figura 2. Tratamiento antibiótico específico para meningitis bacteriana adquirida en la comunidad

Fuente: (Tolosa-Quintero, 2020)

\section{Corticoesteroides}

Los corticoesteroides estabilizan la barrera hematoencefálica y reducen la resistencia al flujo de salida de LCR, lo que resulta en una disminución de la presión intracraneal. La dexametasona es el corticosteroide que se recomienda con mayor frecuencia en la meningitis bacteriana debido a su capacidad de penetrar la barrera hematoencefálica, para ayudar a modular la respuesta inflamatoria del huésped y prevenir las complicaciones neurológicas de la meningitis bacteriana, especialmente la pérdida de audición, pero su uso es controversial. La evidencia disponible respalda el uso de 
dexametasona coadyuvante en lactantes y niños con meningitis por Hib. La dexametasona debe iniciarse 10-20 min antes o concomitante con la primera dosis antimicrobiana, a una dosis de $0,15 \mathrm{mg} / \mathrm{kg}$ por dosis por vía intravenosa cada 6 horas durante 2 o 4 días. Pero no debe administrarse a lactantes y niños que ya han recibido terapia antimicrobiana y debe suspenderse si el paciente no tiene meningitis bacteriana o si la bacteria que causa la meningitis es una especie distinta de Hib (Tolosa-Quintero, 2020, pág. 16).

\section{Metodología}

La metodología de la investigación, es una revisión bibliográfica apoyada en medios electrónicos como páginas web (SCOPUS, PubMed, Biblioteca Cochrane, Google Scholar), en donde se encontró una amplia variedad de artículos de investigación que abordan la temática estudiada, el objetivo es recopilar la información más relevante de dichos autores para realizar una síntesis bien completa, que pueda ayudar a futuras investigaciones.

\section{Resultados}

\section{Caso clínico}

Rodríguez-Martínez, Roselló-Guijarro, López-Medina, Giner-Almaraz, \& Piqueras-Arenas (2020), presentan caso de niño de 10 años, que fue remitido de un centro hospitalario por sospecha de meningitis bacteriana, con los siguientes sintomas:

- Rigidez de nuca.

- Fiebre.

- Somnolencia.

- Vomito.

Exámenes realizados:

- TAC cerebral, resultado normal.

- Punción lumbar, resultado: fallida.

- Hemocultivos, tinción de Gram y cultivo bacteriológico LCR, fueron negativos.

- La reacción en cadena de la polimerasa (PCR) Multiplex Filmarray en LCR detectó la presencia de ácido nucleico de $\mathrm{N}$. meningitidis.

- La aglutinación de látex con antígenos capsulares serotipo a N. meningitidis serogrupo B.

A las 48 horas, el tercer día reinició la fiebre, persistía la somnolencia y se detectó limitación a la rotación interna de la cadera derecha. La resonancia magnética (RM) cerebral mostró aumento de intensidad de señal de la sustancia blanca periventricular y realce frontoparietal bilateral. La RM de cadera evidenció derrame articular e hiperintensidad de señal del obturador interno, externo y glúteo mayor. Se le repiten los siguientes exámenes:

- Artrotomía de la que se extrajo un líquido purulento, cuyo cultivo bacteriológico resultó negativo.

- Tinción de Gram se observaron diplococos Gram negativos y la PCR Multiplex Filmarray en LCR detectó la presencia de ácido nucleico de N. meningitidis.

La evolución posterior del paciente fue favorable, con normalización clínica; aunque a los 21 días de ingreso persistía fiebre, con progresiva anemia y leucopenia. Se sospechó toxicidad farmacológica, por lo tanto, se retiró la antibioterapia y se administró naproxeno sin respuesta, por lo que se pautaron dosis bajas de corticoesteroides con lo que se logró la remisión de la fiebre. El estudio inmunitario (que incluyó la determinación de complemento sérico) fue normal (Rodríguez-Martínez, Roselló-Guijarro, López-Medina, Giner-Almaraz, \& Piqueras-Arenas, 2020, págs. 1632-1633).

Mateo Chávez (2018), en su trabajo de investigacion, analizo a 146 neonatos, que nacieron con meningitis y fue detectada en promedio a los 10 dias. El 59,72\% de los casos, los factores de risgo asociados al de- 
sarrollo de la meningitis fueron: : Infección de vía urinarias o leucorrea documentada en el último trimestre de embarazo, entre los hallazgos clinicos mas relevantes: inestabilidad térmica $42.46 \%$, taquipnea $34.24 \%$, irritabilidad 30.82\%); e hipotensión $15.75 \%$ de los casos.

Se encontraron en el $76.71 \%$ de los neonatos con leucocitosis. Los valores de glóbulos blancos oscilan entre $10.00 \times 109 / \mathrm{L}$ a $68.07 \times 109 / \mathrm{L}$; con una media de $8.19 \times 109$ /L. Cabe mencionar que se reportaron 5 casos de pacientes con leucopenia menos a $4.5 \times 109 / \mathrm{L}$, sin embargo estos valores no se relacionaron con la mortalidad a las 48 horas. Se encontró que los niveles de procalcitonina en muestras de sangre periférica estaban elevados $>0.5 \mathrm{ng} / \mathrm{dL}$ en 70 (47.94\%) neonatos; estos fluctuaron entre $0.51 \mathrm{ng} / \mathrm{dL}$ a $43.0 \mathrm{ng} / \mathrm{dL}$, con un promedio de $3.71 \mathrm{ng} / \mathrm{dL}$. Estos hallazgos no tuvieron relación con el mal pronóstico de los pacientes. El análisis de LCR demostró que 51 pacientes presentaron niveles de glucosa en LCR 170 mg/dL. La concentración de proteínas en LCR entre los pacientes que presentaron mal pronóstico varió entre 155 $\mathrm{mg} / \mathrm{dL}$ a $1301 \mathrm{mg} / \mathrm{dL}$.

En cuanto al análisis de crecimiento bacteriano, se obtuvo cultivos positivos de sangre en el $19.17 \%$ de los casos y líquido cefalorraquídeo en el $3.42 \%$ de los casos, incluyendo un $2.05 \%$ de casos con un cultivo positivo en sangre y líquido cefalorraquídeo. Las bacterias identificadas como el agente causal de la meningitis fueron: Staphylococcus epidermidis en 9 casos; Staphylococcus haemolyticus, 4 casos; Escherichia coli, 3 casos; Klebsiella pneumoniae, 3 casos; Staphylococcus hominis, 3 casos; Acinectobacter baumanii, 3 casos; Citrobacter koseri, Enterobacter cloacae, Enterococcus faecalis, Listeria monocytogenes y Streptococcus agalactiae presentaron 1 caso respectivamente.
De acuerdo con la definición de la escala GOS, los pacientes fueron clasificados en dos grupos en base a los resultados: buen pronóstico, el 71.23\% o mal pronóstico un 28.76 de los casos. El grupo de mal pronóstico incluyó la mortalidad en 5 pacientes, discapacidad grave en 4 pacientes y discapacidad moderada en 33 pacientes (Mateo Chávez, 2018, págs. 36-42).

\section{Conclusiones}

La meningitis bacteriana es una afección que debe diagnosticarse dentro de las primeras 48 horas, ya que su evolución y pronostico son inciertas. Es por ello, que el diagnóstico oportuno, así como el estudio de los factores externos que la provoco, es fundamental para evitar un agravamiento de la condición del paciente. Después de que se confirma el diagnóstico de la meningitis, se debe iniciar el tratamiento con antibióticos empíricos, esperando la identificación del tipo o subtipo de meningitis por los departamentos de microbiología. Si luego de iniciado el tratamiento se logra estabilizar al paciente y supera la enfermedad, es probable que se puedan generar secuelas neurológicas, es por ello que es vital el seguimiento y control de la evolución del paciente para seguir con su recuperación.

No hay que olvidar que la meningitis bacteriana se puede contagiar, por secreciones respiratorias y salivas, mas por el contacto íntimo. Sin embargo en la mayoría de los casos la misma respuesta inmunológica del cuerpo humano combate a la bacteria y la elimina, en los casos donde se produzca un contagio. No se debe olvidar los protocolos de inmunización contra la meningitis los primeros días de vida, para evitar el contagio y propagación de la misma. En el primer caso clínico se confirman algunos síntomas descritos en la bibliografía como fiebre y rigidez en la nuca, así como la administración de antibióticos como tratamiento. En cuanto al caso de los neonatos se confirma como agentes bacteriales que están descritos en

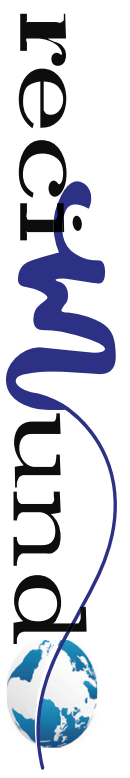


la bibliografía internacional como Staphylococcus haemolyticus, Klebsiella pneumoniae y Staphylococcus hominis, por nombrar los más relevantes.

\section{Bibliografía}

Caballero, M. M., García, M., González, R., Fuentes, M., \& Díaz, D. (2017). PROTOCOLO DE MENINGITIS BACTERIANA AGUDA.

Fajardo Barreto, C. A., \& Guevara García, G. (2018). Protocolo de cuidados de Enfermería en pacientes con Meningitis Bacteriana .

Mateo Chávez, M. B. (2018). FACTORES DE MAL PRONÓSTICO EN PACIENTES DIAGNOSTICADOS DE MENINGITIS BACTERIANA NEONATAL EN EL HOSPITAL DE NIÑOS ROBERTO GILBERT ELIZALDE EN EL PERÍODO 2013-2016 .

Merchán Beltrán, P. D. (2020). Meningitis bacteriana en población pediátrica.

Moreira, F. J., Moreira, J., Villacis, M., Romero, V., Intriago, M., \& Mera, M. (2019). Riesgos y cuidados a los pacientes diagnosticados con una meningitis bacteriana. RECIMUNDO, 3(4), 417-437.

Neira Serrano, I. J. (2019). Abordaje integral con criterios clínicos, diagnósticos y terapéuticos para el manejo de meningitis bacteriana en pacientes mayores de 1 año.
Rodríguez-Martínez, M., Roselló-Guijarro, M., López-Medina, E., Giner-Almaraz, S., \& Piqueras-Arenas, A. (2020). CASO CLÍNICO-Manifestaciones extracraneales asociadas a meningitis bacteriana en un hospital pediátrico terciario. Revista de Enfermedades Infecciosas en Pediatría, 32(131), 1631-1636.

Solórzano, C. G., Pincay, M., Andrade, I., \& Domínguez, M. (2018). Proceso de atención de enfermería aplicado en paciente con meningitis bacteriana bajo el modelo de Sor Callista Roy. RECIAMUC, 2(3), 154-173.

Tolosa-Quintero, D. (2020). aracterísticas clínicas y microbiológicas de pacientes con meningitis bacteriana en un hospital pediátrico en Bogotá, Colombia: 2008-2017.

Uribe-Ocampo, A., Correa-Pérez, S., Rodríguez-Padilla, L., Barrientos-Gómez, J., \& Orozco-Forero, J. (2018). Características clínicas, epidemiológicas y manejo terapéutico de la meningitis pediátrica en dos instituciones de Medellín, Colombia. Universidad y Salud, 20(2), 121-130.

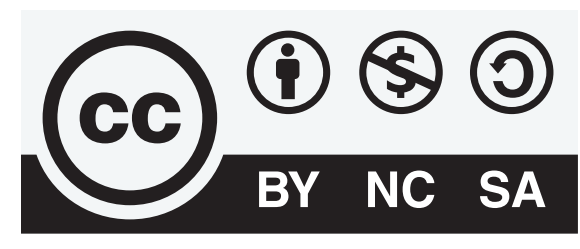

CREATIVE COMMONS RECONOCIMIENTO-NOCOMERCIAL-COMPARTIRIGUAL 4.0.

\section{CITAR ESTE ARTICULO:}

Beltrán Parreño, K. S., Guerra García, A. A., Parra Parra, P. D., \& Huanca Jumbo, K. E. (2021). Meningitis bacteriana en paciente pediátrico. RECIMUNDO, 5(4), 45-52. https://doi.org/10.26820/recimundo/5.(4).oct.2021.45-52 